\title{
PROOF
}

\section{5 \\ The Intermediaries in the Risk Capital Industry}

Alessandro G. Grasso

\section{Introduction}

Young plants and animals require specific environmental conditions or special forms of nourishment. It appears that young innovative firms are similar in having distinctive financing needs, which have to be covered by the right amount of the correct type of financial resources. Like infants, firms of this kind may have difficulty in communicating with their nurturers (problems of information asymmetry are particularly acute for this type of firm). To overcome these problems proportionally more attention has to be paid to sourcing the most suitable forms of finance.

Financing by means of risk capital is particularly important. Being able to call on specialists to provide investment intended to generate value greatly improves the results that can be achieved. Financial resources in this category - principally venture capital and private equity - support the birth of new business, allow the implementation of new strategies and corporate acquisitions, and sustain firms in crucial periods, such as generation handovers and other particularly difficult times in their life cycles.

This chapter takes a more detailed look at the risk capital industry, investigating the taxonomy of this area of the financial industry, the players involved and its distinctive features. The argument is relevant since, as chapter 6 shows, this sector is enjoying considerable success, reflected by the growing mass of funds invested. This success has attracted the attention of the academic world and more recently of policy-makers interested in creating conditions that favour the development of a dynamic, innovative entrepreneurial environment. 


\section{PROOF}

62 Alessandro G. Grasso

This chapter is divided into five sections. The first discusses a number of definitional problems, while the second describes the main types of operator active in the risk capital industry. The third section introduces the principal categories of operations, after which the next section focuses on the main kinds of risk involved in this activity. Finally, the investment process is examined in greater depth.

\section{The definition: a critical issue}

Any analysis of this source of financing requires a definition of what investment in risk capital entails. For our purpose, investment in risk capital defines the operations of professionals who purchase shares in the capital of firms which offer the prospects of growth, with the aim of achieving a capital gain when the shares are later sold. The underlying business principle is very simple: 'buy low and sell high' (NVCA, 2007, p. 15).

However, as we look more closely at this sector, we see that although the basic assumptions are the same, operations in this area may vary widely, due largely to the way in which risk capital investors' business practices have developed over time and in a variety of geographical contexts, adapting to the entrepreneurial system and the differing levels of development of the financial markets. The conventional literature describes this evolution by subdividing the various types of operations more or less in relation to the different life cycle stages of the investee firms. Normally, three main phases are identified: start-up, expansion and replacement investment.

While this segmentation is widely used for statistical purposes, the terms venture capital and private equity are also frequently used to define the operations of the various types of professional investors.

In the gradual standardisation of terminology at the international level, venture capital is coming to be seen as a subset of private equity. The definitions proposed by the two longest established investors' associations, the National Venture Capital Association (NVCA) and the European Private Equity \& Venture Capital Association (EVCA), are more or less the same and inform us that private equity is an asset class which consists of equity investment in enterprises not listed on a stock market, while venture capital is, strictly speaking, a subset of private equity and refers to equity investments made for the launch, early development or expansion of a business.

Venture capital investment can be defined as the provision of share capital, or the underwriting of hybrid financing instruments, by 
specialist investors, in the medium-to-long term, in unlisted enterprises in the initial stages of their development cycles, which have high growth potential in terms of new products or services, new technologies or new market concepts. The investment is generally temporary and direct, and involves a minority holding, while the investor contributes financial and other know-how to the firm's development, enabling him to ensure that it increases its value and provides him with a capital gain on exit.

However, in spite of the standardisation of terminology witnessed of recent years, the meaning of these terms is not always absolutely clear, as the NVCA stress: 'there has been some recent confusion about the term private equity referring only to the buy-out/mezzanine portion of the private equity market' (2007, p. 57).

Achieving a clear definition of the meaning and context of this form of investment and the relative sector is no mere linguistic exercise: the lack of a common definition at the international level reflects uncertainty concerning the boundaries of this phenomenon which, together with the low level of disclosure provided by most of those in the industry, has restricted international statistical comparison for a long time and is making it a complex undertaking even today.

With regard to the problems of definition, according to some researchers a number of factors arise from the considerable increase in complexity of the various production sectors. On the one hand, firms' needs can no longer be identified in accordance with the traditional concepts which classify them on the basis of life cycle phase, while on the other, the application of rigid categorisation to the various types of investor is becoming less useful. According to Caselli and Gatti (2002), what really defines an investment operation as one of venture capital is not the life cycle of the investee company or the level of risk undertaken by the investor, but the nature of the risk itself. An operation involves venture capital when the investor assumes the entrepreneurial risk in addition to the financial and operating risks (Figure 5.1). This type of risk

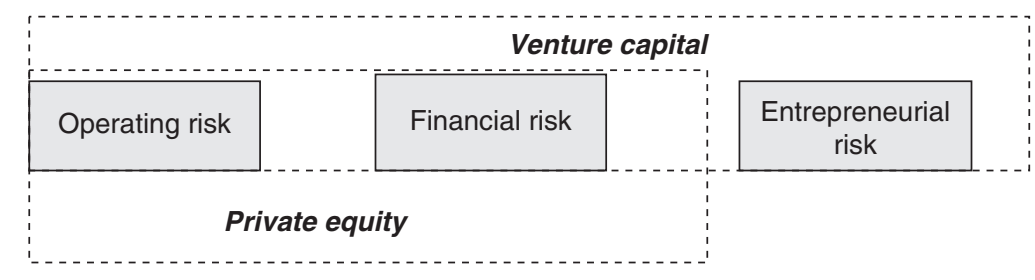

Figure 5.1 The different kinds of risk and the distinction between private equity and venture capital 
is present when the investor's decision to invest in the business is dependent on a modification of the entrepreneurial formula of the company financed.

This factor is undeniably present when a new enterprise is founded, since by definition it must be based on a new entrepreneurial formula, but it also occurs in all expansion investments which allow existing companies to substantially redraw their competitive strategies, generating major changes in their operations. From this viewpoint, venture capital and private equity are two types of investment which succeed each other chronologically, depending on the firm's life cycle stage and the type of risk to which it is subject.

In this chapter, following the EVCA and NVCA definitions we use the term venture capital when looking at the activities of those investors who invest in firms in the phase of the life cycle starting from launch to expansion. Private equity is the provision of equity capital by financial investors over the medium or long term to non-quoted companies with high growth potential; as a consequence, venture capital is to be considered a subset of the general private equity activity.

Therefore, the venture capital investor is a financial intermediary capable of supporting and strengthening a company's growth and assisting it with strategic planning, management recruiting, operations planning or introductions to potential customers and suppliers (Gorman and Sahlman, 1989). In the light of these comments, it is clear that the demand for services linked to venture capital will probably come from new enterprises or existing firms which intend to speed up their growth process significantly.

Venture capital as a source of financing for the start-up and growth of enterprises is of major importance in an economy with a high proportion of SMEs, as in Europe, where companies in this category account for 99 per cent of the total and employ two-thirds of private sector workers. The European Commission (2006b) affirms that their success is inextricably linked with that of the EU.

The segment of private equity which concentrates on buyout/mezzanine operations normally involves acquisitions of mature enterprises, with stable, clearly defined business plans, involving a lower degree of risk than operations in the venture capital segment. In operations of this kind, private equity operators generally use borrowed capital as a source of funds, and the term 'leveraged buy-out' is therefore used. This is a broad definition of the entire series of operations (both strictly corporate and strictly financial in nature) in which the aim is to acquire a company, or sometimes a corporate division, by exploiting the 
borrowing potential of the target company itself. The buy-out is carried through using borrowed capital provided by third parties as the main, and in some cases the only, source of financing. The relative loans are granted on the basis of the ability of the target company to meet the repayment commitments on the borrowed funds from its operating profits or the sale of non-strategic assets. Therefore, due to the large increase in indebtedness which they generate, for leveraged buy-outs to be successful, the efficiency of the target companies must be improved through organisational and managerial restructuring policies, cost-cutting exercises and the reinforcement of core business areas and the sale of those considered surplus to requirements, in order to stabilise cashflow trends.

However, the scale and number of such operations in recent years has drawn attention to the possible consequences of the resulting high levels of indebtedness, which place a large amount of stress on the organisational structure and risk causing a misalignment between the shortto-medium-term objectives of the private equity investors and the long-term aims of the target company. The apparently pitiless way in which they restructure the companies they acquire and their huge profits have created the image of private equity investors as greedy exploiters, relentlessly seeking profits just as 'locusts look for food'. One sign of this was the British General Workers' Union (GMB) protest at the Super Return conference in Frankfurt, which rapidly gave rise to a wide-ranging discussion of the role of the private equity industry (EVCA, 2007a).

\section{The operators}

After our examination of the definition of risk capital investment, it is important to make the high degree of complexity of operations of this kind clear once more. Such investment does not only involve acquisition of a holding in the company's equity or semi-equity, but may also include additional services of varying breadth and depth: strategic and managerial consulting, personnel recruitment, financial know-how and legal, fiscal and accounting advice, as well as assistance derived from the investor's network of acquaintances and relationships.

In view of the scope of these activities, it is useful to understand who the players who undertake risk capital investments are and how they operate, providing a variety of scenarios which will help to define the main characteristics of those involved.

In the international context, the subjects who engage in risk capital investment make up a composite universe; they differ from each other in the legal forms used, the aims pursued and the way in which the funds 


\section{PROOF}

are raised. The differences between the investors found in the different economic contexts have a variety of origins, including the difference in the type of promoter organisation involved, and fiscal, organisational and legislative factors (Gompers and Lerner, 2006).

The first distinction is between institutional and other investors. Institutional investors engage continuously in risk capital investment; as we shall see, they are intermediaries established for this specific purpose, or financial operators which implement a systematic diversification of their asset portfolio. Non-institutional investors engage in operations of this kind on an occasional basis. If the definition is used, business angels, often classed as informal investors, may be further subdivided into the institutional and non-institutional categories, depending on the degree of continuity of their involvement in this investment area.

Another internationally used classification distinguishes between captive and independent investors, depending on the mechanisms used to raise funds for investment (Sahlman, 1990). Captive operators are direct offshoots of other financial or industrial institutions and obtain their capital from the parent company: they therefore do not use the capital market as a source of financial resources and their operating independence is limited. Most players in this category are financial institutions, such as merchant banks and corporate investors. Conversely, independent risk capital investment firms offer their services to a large number of investors; they therefore require results proving their ability to achieve good returns to persuade the potential investors to supply the capital they need. Recently, in response to the interest attracted by this form of investment, there has been an increase in the number of semi-captive firms, which use resources derived from the group to which they belong and from the capital market.

There is a further distinction between public and private investment organisations. For private operators, the aim is either to achieve an economic return or to acquire a technology in synergy with their own core business. Public investment organisations, on the other hand, use private equity and venture capital investments as a tool to support depressed geographical areas and disadvantaged industrial sectors, and to support the economy and employment in more general terms. This is demonstrated by the fact that, as we shall see in chapter 8 , the role of public investment organisations is very closely correlated to the degree of development of the private sector, since its aim is to cover the areas of business where the latter is not active.

A more detailed classification can be drawn up on the basis of legal/organisational structure and operating characteristics (Table 5.1). 
Table 5.1 The operators in the risk capital industry

\begin{tabular}{ll}
\hline Type of operator & Principal type of investment \\
\hline a) Business angels & Initial start-up stages \\
b) Incubators & Initial start-up stages \\
c) Corporate venture capitalists & Venture capital \\
d) Closed end funds & Private equity and venture capital \\
e) Investment firms & Private equity and venture capital \\
f) Merchant banks & Private equity \\
\hline
\end{tabular}

Below we briefly examine these operators' main characteristics, focusing on the investors involved in the early stages of the enterprise's life cycle. Generally speaking, it is useful to remember that business angels and incubators usually engage in risk capital investment operations involving the first stages of the enterprise's life cycle: the seed, start-up and early stages. The other operators usually intervene during later phases. Nonetheless, exceptions can be recorded. As far as public investment organisation is concerned, they may be structured as closedend funds or genuine venture capitalists. They often take the form of public-private partnerships.

\section{Business angels}

In the US and UK, where business angels are an established part of the financial scene, they are generally described as subjects with financial resources, managerial skills and a wide range of acquaintances, which they make available for the development of a business. This category is often referred to as the 'informal venture capital segment'. Since many operators in this sector wish to remain anonymous and not provide information about their investment activities, the lack of objective data makes it impossible to produce statistics representative of the entire sector and, as the European Commission (2003c) reminds us, we must be very cautious when drawing conclusions. This is because the market in which business angels operate is extremely heterogeneous: while some subjects make investments in a range of $€ 500,000-1$ million, there are also networks of business angels investing up to $€ 4-5$ million. Some of these operators may find themselves competing with venture capital firms. Syndicated operations by business angels are becoming more and more common, especially in the UK and Canada, where the US development model is being adopted (European Commission, 2003c). 
Various studies inform us that business angels can play a very important role in reducing the problems of information asymmetry which may discourage traditional financiers, banks and even venture capitalists themselves. ${ }^{1}$ By making early stage investments, they can help to facilitate access to other types of financial resources and thus assist in closing the equity gap. Their role is not merely that of suppliers of capital: they provide firms with formal and informal advice and mentoring, which is often an even more important contribution to their development than the capital itself: in this stage, the enterprises' financial needs may still be small, but their need for know-how is immense.

In the US, the role played by business angels in the seed and early stage operations is important: in 2005 they participated in about 50,000 projects, with an average investment of $\$ 5$ million (Committee on Small Business House of Representatives, 2006). Unfortunately, the lack of reliable data on business angels' interventions do not permit us to evaluate the role played by informal investors in Europe.

More and more countries are introducing tax incentives to encourage potential business angels to purchase shares in SMEs. For example, the British government allows investors to deduct part of their investments from their income tax liability and to obtain tax exemptions on their capital gains. In the US, significant tax breaks on income tax, and especially on capital gains, have fostered the consolidation of the business angel system, with the benefits described above.

\section{Incubators}

This category of investors is more diversified than that of business angels, although they too provide support for the launch and development of new business ventures. The sector's complexity becomes apparent when we consider the classification of the possible different types of incubators in terms of structure, services offered and objectives. A distinction can be made between independent, private (profit-oriented) incubators, public (non-profit) incubators and incubators originating from the university system.

The founders of profit-oriented incubators may be individual entrepreneurs, private industrial groups or financial institutions, which assess the investment on the basis of profit only. The activities of corporate incubators are often in synergy with those of the companies which founded them. The companies admitted are selected on the basis of criteria which depend to a large extent on the purposes for which the incubators were created. They contribute to the success of start-ups in a variety of ways, one of which may be placing their own specialist staff 
in the various firms. They have close links with the risk capital market and adopt equity business models, investing in the firm's share capital or charging for the services supplied.

Non-profit incubators make premises and various services available to innovative firms at cost price, or in some cases free of charge. Their function is usually to develop new business initiatives and create new employment opportunities in particularly disadvantaged areas, where local government institutions hope to generate progress by this means. $^{2}$

Lastly, university incubators are founded with the aim of encouraging interaction between university research and the world of business. The main intention is to bring research out of the university by encouraging the use of its results as the basis for the formation of companies, and promoting the application of research findings in industry. University incubators are generally non-profit and are located on campuses. They may be part of the university organisation itself, or run by university consortia. Unlike the other models, they have strong links with the world of research and often focus on specific areas in which the university that created them excels, such as nanotechnology, biotechnology, life sciences, and so on.

While the number of private incubators has decreased over time, the number of university incubators has gradually risen.

Over the years there has been a profound evolution in the role played by incubators, their organisations and the services offered, and there are currently sometimes considerable differences between the functions they provide: premises and shared resources, specialist services and networked knowledge.

Incubators differ from both business angels and venture capitalists in the completeness of the accessory services supplied (from assistance in drafting the business plan to the sharing of technological resources, assistance with accounting services, legal and tax consulting, assistance in implementation of the marketing plan, and so on), since they serve ventures still in the seed capital stage or, in the most extreme cases, projects which are still more business ideas than enterprises as such.

\section{Corporate venture capitalists}

They are captive operators, generally the specialist divisions of large industrial corporations. They are therefore highly specialised in the various high-tech sectors such as life sciences, biotechnology, information technology and telecommunications. Their operations may take many 


\section{PROOF}

different forms, involving the acquisition of minority or majority holdings, almost always through an increase in the capital of the investee company. This particular investor's final objective is not the generation of a capital gain, but rather the acquisition of the financial venture by the parent company.

\section{Closed-end funds}

Closed-end funds are financial intermediaries which raise funds for professional joint investment purposes through the sale of shares. These funds are a vehicle both for the collective investment of savings and for the raising of huge financial resources from institutional investors and corporations. The fact that they are closed-end makes this type of instrument particularly suitable for the medium-to-long-term investments typical of private equity and venture capital operations.

Funds of this kind, traditionally the most common category of investor, often enter into limited partnerships, which we discuss below. Their management strategies depend on the regulatory framework in each country: in some states, they are obliged to diversify their investment portfolio, while in others their managers have complete freedom of action. Some closed-end funds are prepared to invest in any stage of the enterprise's life cycle, while others are more specialised, focusing their activities on individual industrial sectors, enterprise life cycle stages or geographical areas.

Apart from their closed-end nature, instruments of this type have other features which make them particularly adaptable and effective for risk capital investment activities:

- The separation between the fund and the company which manages it; the fund invests third-party capital. This allows the management team to act independently and select what it considers to be the best investment opportunities, and reduces the decision-making time involved in the preparation and finalisation of investments. Within the fund's organisational structures, the managers' priority objective is the optimisation of the risk/return combination. As we shall see, this is facilitated by incentives (carried interest) which give an entrepreneurial aspect to the fund managers' role.

- The fund's pre-set life: The life cycle of the closed-end fund, which will be wound up when the shares are liquidated, enables investors to see the real outcome of the operations in the form of the return generated, within a pre-defined time scale. 


\section{Investment firms}

They engage in merchant banking activities, but are not directly derived from banks; rather, they are independent operators which work as companies and obtain the funds needed for their operations from institutional investors.

Although apparently similar to closed-end funds, investment firms differ from them above all from a formal point of view, since the assets they manage are the capital of the company itself. Each investor is therefore also a shareholder in the investment firm.

From an operational point of view, they are able to undertake the same operations as a merchant bank, but the focus is different because their main activity is the acquisition of lasting holdings in the capital of new enterprises, in both the initial and later stages of their development.

\section{Merchant banks}

Merchant banks are captive organisations, part of the banking system, which supply various financial services. These include share acquisitions, financial consulting, assistance in extraordinary financial operations (mergers, acquisitions and restructuring) and assistance during the initial public offering (IPO). The distinctive features of merchant banks in the risk capital market are linked to the fact that there are no limits on operations in terms of time and quantity. Moreover, they can obtain a return in terms of both capital gain and fees for the advisory services they provided.

It is therefore clear that risk capital investment is not merchant banks' core business, but merely one of their areas of activity.

The proportion of the venture capital market occupied by each of the types of operator described above is different in each country. In the US and the UK, the majority of venture capitalists are structured as single companies that manage several funds simultaneously, each legally distinct from the other, in a limited partnership. As mentioned, the success of this organisational structure is essentially due to the fiscal advantages that can be obtained. In continental Europe, the prevalent structure is the closed-end fund, similar in many respects to the limited partnership found in the US and UK (EVCA, 1999).

\section{Types of operation}

Risk capital operations undertaken at different stages in the development of a company vary in financial scale, prospects and underlying 


\section{PROOF}

72 Alessandro G. Grasso

assumptions, and are the outcome of the combination of two key features of this type of investment business: the availability of capital and know-how. As mentioned above, apart from the standard distinction based on legal/organisational form, there is a further segmentation of the risk capital market which distinguishes between types of operation on the basis of the target enterprise's life cycle stage.

Operations, and the relative risks accepted by the investor, are subdivided into:

- start-up financing;

- expansion financing;

- change (or replacement) financing.

As the firm's maturity increases and it moves on from one stage to the next, the capital needed to carry out the operation and the know-how required change, and the level of risk involved also varies.

\section{Start-up financing}

This category includes all operations intended to support the birth of a new enterprise, in both the seed and the very early launch stages. Vesper (1993) produced a model which identifies a number of essential steps to be performed during the creation of a firm: those involved must take the opportunity, perfect the idea, protect against copying, establish the team, obtain financing, start up the business and launch the product. Application of this model to the venture capital context enables us to define the specific characteristics of investments of this kind: in the startup stage, they constitute more a contribution to defining the business plan than a financial operation as such.

A widely accepted classification breaks down start-up operations by development sub-stage:

- The term seed financing is used when the investor is involved as early as the trial stages, when the entrepreneur has an idea or an invention rather than a product. The technical worth of the product or service is not proven and often the investor is working with someone who is not yet an entrepreneur in the sense of acquiring the necessary skills. Generally, the strategy and business plan have not been drawn up and the operator requires managerial, technical and scientific know-how.

- The subsequent start-up stage is when production begins, even though the commercial worth of the product/service has still not been 
absolutely established. Compared to the previous phase, trials have now been completed and the product has been developed and verified. The bases for founding a business are thus present.

- Finally, first stage financing supports the speed-up of the growth in production.

From this we can see that, in the initial stages, the new enterprise requires both financial resources and technical know-how; this explains why these stages are dominated by business angels, incubators and corporate venture capitalists.

\section{Expansion financing}

This risk capital investment area includes investments intended to increase the rate of development and expansion of enterprises which have successfully concluded the crucial start-up stage. These investments have a lower level of risk than those in the initial start-up stages, since the investee companies have an organisational structure and a portfolio of products/services which have been presented on the market with some degree of success, as well as established relationships with both suppliers and customers. Due to these factors, prior assessment of investments made in this stage is less problematic.

Generally, three types of operations are included in this category:

- Second stage financing. Once the commercial worth of the prod$\mathrm{uct} / \mathrm{service}$ has been verified, the investor provides funds to increase the production capacity and sales. The aim is to speed up the enterprise's growth. In this stage, the firm is starting to generate cashflows, but new funds have to be raised to support the additional investments needed to achieve optimal growth.

- Third stage financing. The company is now in a position where it has to consolidate its growth by defending its position against competitors and developing new plans and strategies. These may include the launch of new products, expansion and diversification of production or distribution operations, or the acquisition of competitor firms.

- Fourth stage financing. The investor puts his funds into a mature company with consolidated positions. These investments are often over even shorter time scales but are of a larger size, made before the company takes major steps such as stock market listing or a merger. In investments of this kind, the financial aspect is of much greater importance than the investor's management input. 


\section{PROOF}

74 Alessandro G. Grasso

\section{Change (or replacement) financing}

The third category of risk capital investment is intended to finance the processes by which the firm consolidates the competitive positions it has acquired, and often coincides with changes of varying importance in the company's ownership structure. Investments in this category are more independent than the others we have seen of the stage the company has reached in its development. Here again, the literature identities various sub-categories:

- Replacement capital is the term used when the investor buys into the firm to replace minority shareholders wishing to dispose of their holdings, whose departure does not signify a major change in the company's strategy.

- A buy-out involves a radical change in the company's ownership.

- Turnaround financing is undertaken when the company is in serious financial difficulty, which can only be solved through radical action on the part of the owners and/or managers. Here the project is one of financial, and more often operational, restructuring of the target company. Therefore, as well as capital, the investor contributes professional know-how, which assumes considerable importance. Turnaround operations thus often take the form of management buy-ins, in which the investor provides financial resources and puts in place a new management, given further incentives through participation in the business risk.

\section{Types of risk undertaken}

As we have seen, the risks undertaken by a risk capital investor are high, although they are theoretically lower in the case of development, growth consolidation, mezzanine and buy-out operations. In the case of venture capital operations, on the other hand, investments are intended to develop new business ideas, and new products or technologies not yet, or not fully, proven. The abilities of the entrepreneur, who is often young, are thus crucial to the success of the project. Moreover, in most cases, and in the early stage in particular, the enterprise has few or no assets which can provide the financier with collateral, although anyone operating in this sector is not interested in collateral as the basis for an investment.

As well as the strictly financial risks involved in the provision of risk or debt capital (which are thus not specific to venture capital, since they 
are the same in other forms of investment), unlike other investments, venture capital projects also involve:

- A product risk, deriving from the nature of the business; this is particularly high in the early stage, because the venture capitalist makes his investment at a time when the technical soundness of the business itself still has to be verified.

- A market risk, related to the size and structure of the demand for the business being financed and the company's position in relation to any competitors; here again, the early stage is particularly problematic as the business's commercial soundness is still uncertain.

- A managerial risk, deriving on the one hand from uncertainty regarding the entrepreneur's ability to bring his business into being successfully, and on the other from the fact that his contribution to achieving this is essential. Once again, this risk is particularly high in the early stage, because the entrepreneur is the holder of the idea underlying the project and the technical means for bringing it about.

These risks, present during the initial stages of the company's life cycle, explain why seed and early stage investments can be so unattractive (as they require large amounts of know-how and professional skill) and why such high returns are possible, although in most cases they are not achieved.

Figure 5.2 illustrates the entire investment cycle. It shows that the cashflow reaches its lowest ebb in the central stage of the seed phase of the start-up, when investments have to be made to start the business ( $R \& D$ and creation of the organisational, production and sales structures) and earnings are still minimal.

The studies ${ }^{3}$ reveals that there is a grey area, the so-called equity gap, in which business angels and incubators are no longer able to support the investee's growing financial needs, but institutional investors (closedend funds, investment firms and merchant banks) are not yet involved. Due to the particular profile of the investment, with high levels of uncertainty and information asymmetries, which require specific technical skills and know-how, and also the dimensions of the operation (still too small to provide satisfactory returns in relation to the level of risk involved and the agency costs incurred), investors in these last-named categories normally prefer not to invest in firms in this phase of their growth cycle.

The uncertainty and information asymmetries are even greater in the case of innovative SMEs (ISMEs), making it even more difficult for 


\section{PROOF}

76 Alessandro G. Grasso

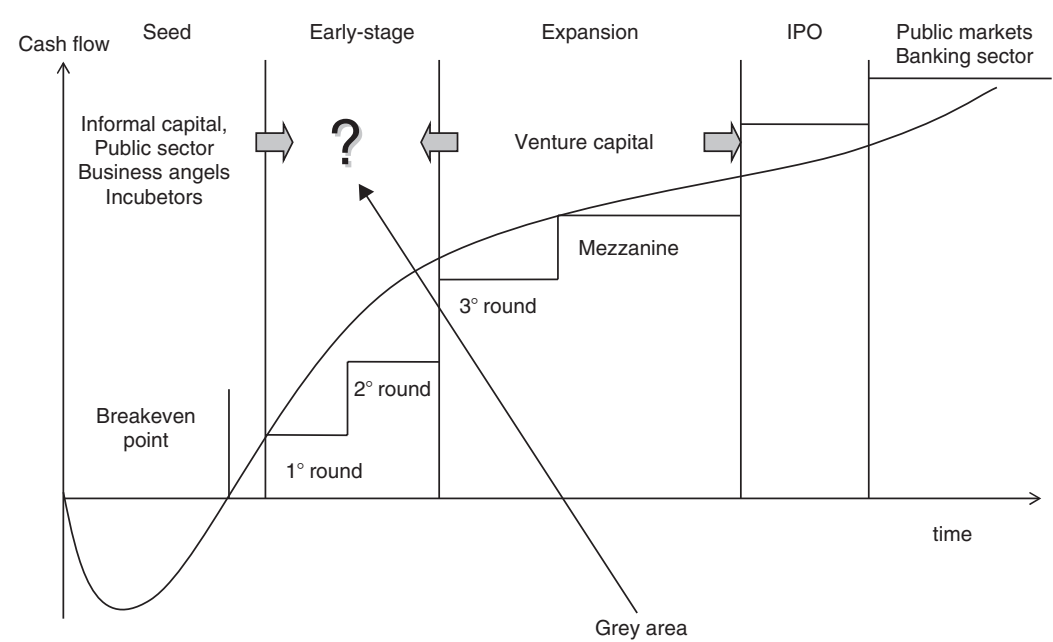

Figure 5.2 The entire investment cycle - the existence of the equity gap Source: European Commission (2005a, p. 8).

them to access funds. Earnings cannot be quantified with any degree of certainty and are extremely variable, while returns are low, especially during the early stage. Moreover, the evaluation of firms in this stage is particularly problematic: a large proportion of their assets are intangible and difficult to evaluate in monetary terms before they have generated positive commercial returns. Financing ISMEs is therefore considered riskier, due to the difficulty in overcoming the problems of information asymmetries. This has led to the proliferation of government initiatives to attempt to fill the equity gap facing innovative firms, as described in chapter 8 .

\section{The investment process in private equity and venture capital}

An operator making an investment in risk capital ${ }^{4}$ implements a strategic plan with a beginning, duration and end. The fact that these investors work to a limited time horizon means that when the potential investment is assessed, it is essential to define its possible performance and to forecast all possible future scenarios in order to evaluate the compatibility between the expected return and the riskiness of the target investment. The meaning of the term 'strategy' is the subject of much discussion in the literature; here, by strategy we are referring to a system of specific 


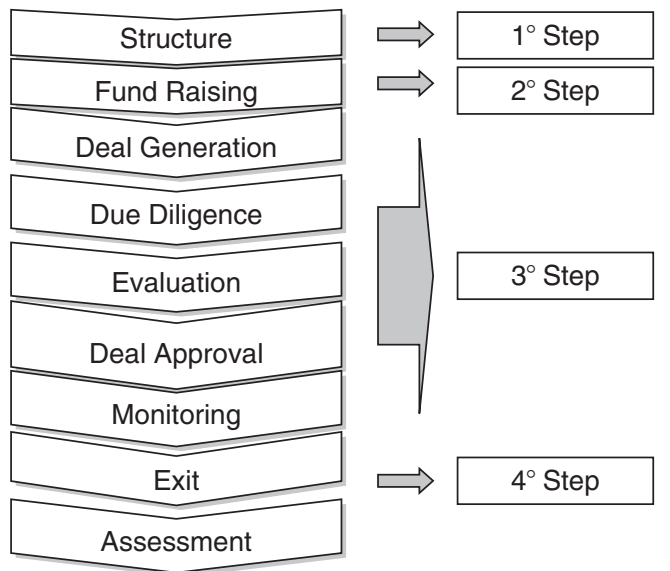

Figure 5.3 The operating cycle of a risk capital investor

objectives intended to guide medium-to-long-term development decisions. This concept must not be confused with management planning. The difference lies in the fact that the strategy sets the system of aims to be achieved, while planning decides the actions and tools needed to attain them. Thus, the strategy is agreed first, and planning and action then follow. The appropriate term for a risk capital investment is thus strategy, since the investor is undertaking an operation with a limited time scale.

Many studies 5 have investigated the fund-raising, deal finalisation, monitoring and exit stages of investments of this kind. In-depth analysis of investors' operations has allowed us to draw up a figure illustrating the operating cycle of a risk capital investor (Figure 5.3).

For the purposes of this chapter, the operating cycle of a risk capital investor can be summarised in the following steps:

1 organisational structure;

2 fund-raising aspects;

3 phases related to the investment process as such: origination, evaluation, acquisition of the holding, management and monitoring of the investment;

4 decisions related to the exit strategy.

From the organisational point of view, the structure adopted by many independent or semi-captive investors at the international level is the 


\section{PROOF}

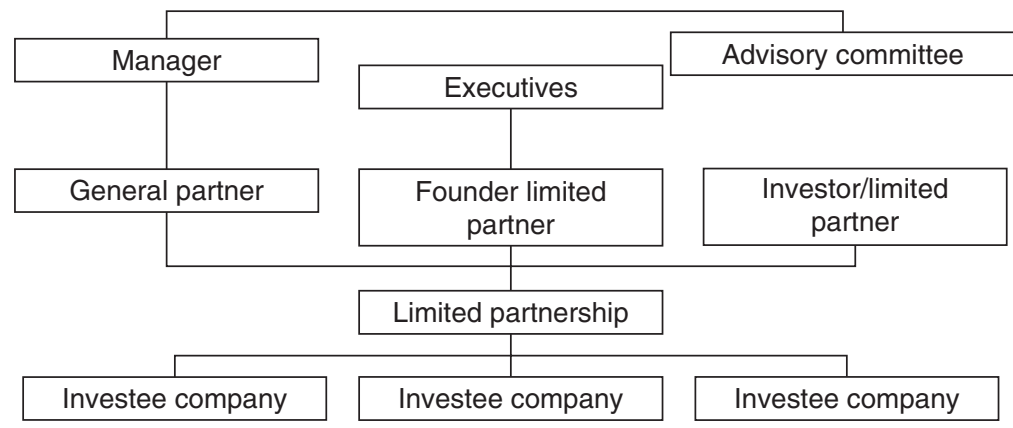

Figure 5.4 The structure of the limited partnership

limited partnership (European Commission, 2006a), which is a contract between two clearly identified parties: the limited partners and the general partners (Figure 5.4). The institutional investors, who supply the capital, are the limited partners, while the professional private equity managers or venture capitalists act as general partners and are responsible for management of the funds received. The limited partnership has a pre-set duration (normally ten years), during which the general partners select the deals, structure the operations, perform monitoring so that action can be taken if the investees' performance falls below expectations and study the best ways out in the interest of the limited partners. In exchange, they receive a management fee to cover the routine overheads, and above all a share of the return generated by the investment (carried interest). This type of remuneration structure limits the problems of moral hazard between the limited and general partners. It must also be said that, since they are independent investors, the general partners will be interested in raising new funds by establishing new limited partnerships, and will only be successful if they can show a track record in line with the risk/return profile required by investors.

In addition to limited partnerships, there are other forms of organisation in general use, such as venture and development capital investment trusts (VDCITs) and venture capital trusts (VCTs) found in the UK. Trusts are listed closed-end funds. VCTs are a particular kind of private equity fund, where the profits distributed to investors enjoy lower rates of taxation in exchange for constraints on the type of investments chosen. They have been developed with two clear aims: to encourage investment in the venture capital of young companies; and to attract non-professional investors towards this sector of asset management. 
Fund-raising is of fundamental importance for the subsequent implementation of the investment strategy. The fund-raising strategy must therefore be carefully planned, profiling the category of investors who may be interested in the project and deciding the best approach to adopt. The main fund-raising channel is the network of relationships between the project's promoters and the potential investors. The fund-raising strategy will vary depending on whether or not the operation is the first time those involved have worked in this area. The operator normally starts to raise new funds when the vehicle used is almost ready for full investment and the track-record of the operations performed is available for examination. It is important to note that when an investor, such as the limited partner, undertakes to pay in a given amount of capital, this amount is the theoretical maximum investment. Generally, the venture capitalist will request the sums needed to finance the investments approved in such a way as to minimise the funds granted and not invested in order to maximise the internal rate of return. These transfers from investors to venture capitalists are called draw-downs.

Gompers and Lerner (2006) underline various factors influencing fundraising policy, such as changes in regulations which may affect specific categories of investors (for example, pension funds), possible changes to tax law, the performance of the global economy and the operator's reputation.

For 2006, according to EVCA, in Europe pension funds were the largest contributor to the funds raised, followed by fund of funds, banks and insurance companies, as outlined in chapter 6 . In the US, the situation is quite different, with an important role played by private individuals investors and academic institutions.

Sources of venture capital and private equity funds also differ across countries; for example, banks are particularly important in Germany and Japan, corporations in Israel and pension funds in the UK (Mayer et al., 2004). In fact, in Germany, banks are by far the most important source of finance for the venture capital industry, and pension funds are conspicuously absent. By contrast, in the UK pension funds, other institutional investors and individual investors provide funds to as many companies as banks. Contrary to popular opinion, government (typically local authority) funding plays a more important role in the UK than it does in Germany and is negligible in the other countries. Funds for the Israeli venture capital industry come from a wide variety of sources, with industrial corporations (typically from the US) being the single most popular source. In Japan, non-banking financial institutions (for example, securities firms, credit card or leasing companies and mortgage institutions) 


\section{PROOF}

80 Alessandro G. Grasso

are the single most important category of finance, followed by banks and insurance companies. Venture capital funds in Germany tend on average to use fewer sources of funds than venture capitalists in other countries; by contrast, funds in Israel, Japan and the UK tend to use a large number of sources of finance; in particular, about a third of the UK funds report using at least four different sources.

To understand the complexity of the risk capital investment process, it is worth quoting a statement made by Doriot in 1940: 'Always consider investing in a grade A man with a grade B idea. Never invest in a grade B man with a grade A idea' (cited in Bygrave and Timmons, 1992, p. 12). When choosing his investments, if he is to make choices which are sufficiently rational from a financial point of view in a context with a high degree of information uncertainty, the investor needs the interaction of a number of objective factors (the strict application of selection methods) and subjective ones (experience and intuition). The use of a strict assessment method is vital for the best use of one of the resources in short supply for the venture capitalist: the time needed to manage the investment. The tendency is thus to implement strict pre-selection, with the aim of reducing the number of possible projects considered and optimising the time involved in each. According to NVCA (2007), for every 100 business plans that come to a venture capital firm for funding, usually only ten or so get a serious look, and only one ends up being funded.

The process by which the target company or enterprise project is assessed can be divided into two stages (Caselli and Gatti, 2002):

a) Pre-investment phase, involving assessment of the presence and importance of a number of critical factors which may decide whether or not the investor is interested. This initial screening stage depends to a large extent on the strategic orientation of the risk capital investor: non-profit, profit or strategically oriented.

b) Selection process: this is the central stage of the assessment process, setting the values which will form the focus of the negotiations between the operator and the investee project. In this stage, all the audits necessary for the final assessment of the investment are performed, with evaluation of its current status and above all its future potential. This audit process is known as the due diligence investigation, and is carried out in order to verify the truthfulness and formal correctness of the information on the basis of which the company is evaluated. This complex activity is vital in that it protects the capital invested if it should subsequently emerge that the data used for the assessment, 
supplied by the company or the entrepreneur, were intentionally misleading, triggering errors in the investor's estimate. Depending on the aspects surveyed, the due diligence investigation can be subdivided into:

- Market due diligence, which allows the investor to understand fully the potential and risks of the specific market in which the company operates and its positioning within the market. The market due diligence is developed in order to compare the results with the future plans presented in the business plan of the entrepreneur.

- Environmental due diligence, which considers the legislation and environmental regulations to identify the impact of changes on the company business.

- Financial due diligence, performed to evaluate the economic/financial aspects of the company's plans and define the necessary financing.

- Legal due diligence, which focuses on the problems of a legal nature that may influence the evaluation of the company or business.

- Tax due diligence, which analyses the fiscal aspects related to the company, in order to find potential liabilities and pitfalls.

Once the due diligence phase has been concluded, the main objective of the final evaluation is to set the price, and thus the composition of the capital employed.

The exact composition of the funds which operators use to make their investments varies over time in response to changes in market conditions and financial innovation; it also varies depending on the size and nature of the deal. The funds venture capitalists use for operations involving small firms, usually in the early stages of their life cycle, consist of equity, shareholder loans and sometimes senior amortising debt. The level of indebtedness is usually close to zero. In deals involving mediumsized enterprises, borrowed capital accounts for a larger proportion of the funds used, either as the main or a secondary component, as in the case of mezzanine debt. Deals relating to mature (mainly large) companies have a higher degree of financial leverage, with a complex debt capital structure.

It must be remembered that a risk capital investor, and especially a venture capitalist, does not merely finance a business project; he provides the entrepreneur with a genuine partner. In this sense, private equity is not just an asset class: it actually has a dual nature, as asset class and active investor. In chapter 6 we discuss private equity from the point of view of the returns it is able to yield and offer to investors. 
The type of support in the choice of strategic plans and operating management depends on the nature of both the venture capitalist and the investment. The distinction is usually made between hands-on investors, whose non-financial contributions to the firm are of considerable importance for its growth, and the hands-off variety, who simply supply share capital and monitor the performance of their investment (Sweeting and Wong, 1997).

Risk capital investment can be considered as a hybrid system: a variant of relationship-based financing (Gompers, 1998), which depends on the efficient operation of the arm's length financial system (Black and Gilson, 1998). Investment in risk capital, and especially venture capital, has to overcome a variety of problems. Start-ups, which have not yet built up a reputation on the markets in which they work, or in the capital markets, are faced with the problems of the agency costs arising from the information asymmetries between borrowers and lenders. Relationship-based financing is able to mitigate these factors by encouraging the screening, monitoring and control of the venture-backed firms (Gompers, 1995).

Venture capital investors have four main tools at their disposal for efficient regulation of their relationship with the firm in which they have invested:

- Through stage financing (Gompers, 1995; Sahlman, 1988): the capital is provided in a number of consecutive rounds, often each conditional on the achievement of targets set in advance. In this context, the firm's prospects are assessed on a regular basis. The shorter the gap between financing rounds, the more often the venture capitalist monitors the progress the company has made, providing him with a larger amount of information. In effect, the role of staged capital infusion is similar to that of debt in leveraged buy-out operations: 'keeping the owner/manager on a tight leash and reducing potential losses from bad decision' (Gompers and Lerner, 2006, p. 161).

- The use of special instruments such as convertible preferred shares offers a means of solving the trade-off between providing sufficient incentive for the entrepreneur and allowing the investor to monitor the firm (Gompers, 1997).

- Board representation allows involvement in defining the main lines of the company's strategy, while using restrictive covenants places restrictions on the firm's freedom of action (Kaplan and Stromberg, 2003).

- Last but not least, the use of specific contract clauses, approved at the point of investment, relating to possible disinvestment options, 
reduces the degree of uncertainty about the way out, crucial for the success of the investment (Szego, 2002).

The common denominator in all of these investments is that the investor (venture capitalist or operator in private equity) is not a passive investor, but has an active and vested interest in guiding, leading and growing the companies they have invested in. The aim is to create value through the expertise gained from past investments in other firms.

In the context of private equity, evaluation is never merely a theoretical or abstract term; it always takes the form of a real, effective price, which will form the basis for the transaction.

The price of the deal depends less on valuation methods involving general parameters than on a calculation based on data which are as near as possible to reality and can be tested, leaving it to the market and the negotiations to identify the correct parameter. Therefore, the aim of the evaluation process of the target firm is not so much to estimate its value as to supply a price. This process is therefore also influenced by the negotiations between the parties and the relative bargaining power of each. Consequently, although the literature provides a variety of evaluation methods, at an international level the calculation method most widely used in the private equity and venture capital market is the multiples method, due to the simplicity, immediacy and easily identifiable nature of the parameters considered (Gervasoni and Sattin, 2000).

The exit stage is the final step in the investment process. At the end of the holding period considered appropriate, the investment must be disposed of in order to bring the risk capital operation to completion.

The institutional risk capital investor is a temporary partner whose interest is in achieving a capital gain by selling the holding once the objectives have been achieved. Disinvestment is thus the crucial operation by which the investor disposes of all or part of his holding.

The problems the investor may face are identifying the best time to disinvest and choosing the channel for disposing of his investment.

The moment when the investor disposes of his holding in the firm's equity is almost never decided in advance; it will depend on the company's growth pattern. If the investment is successful, the venture capitalist disinvests when the firm has reached the planned level of development and its value has increased accordingly. If the project is a failure, for example because the new product or technology has not been successfully established on the market, the investor pulls out when he is convinced that the company's financial problems are insurmountable. 


\section{PROOF}

84 Alessandro G. Grasso

The disinvestment channel may be chosen when the initial deal is finalised or selected later: depending on the weight given to the disinvestment strategy when the investment decision is taken, the literature makes a distinction between the path sketcher and opportunist approaches (Wall, 1998). The path sketcher investor plans his exit in advance, and during the lifetime of the investment concentrates his efforts on achieving the pre-set aim; the opportunist investor, on the other hand, does not plan a way out when deciding whether to make the investment, confident that he will be able to obtain the best possible conditions when the time comes to disinvest.

There are several exit models:

- Trade sale (merger and acquisition) through private agreement with varying methods: sale of the holding to new shareholders, industrial or financial; merger with other companies; sale of the holding to the majority shareholder or management.

- Quotation, after a public offering.

- Write-off. This is not an exit strategy as such, but rather the worstcase scenario, in which the value of the holding is written off if the investment ends in bankruptcy.

Choosing the right models and times is fundamental, moreover the decision is affected by a variety of factors. There are external factors, such as the conditions on the financial markets, and internal ones, such as the size of the holding to be disposed of. The situation changes a great deal depending on whether a majority or minority holding is to be sold; a trade sale is generally preferred in the former case, and stock market listing by means of an initial public offering in the latter.

Apart from the external and internal variables, in most cases listing on a stock market is the favoured way out, but careful consideration must be given to its advantages and disadvantages. The main benefits derive from:

- demand from a wide spread of buyers, allowing equity holdings to be disposed of gradually, taking advantage of any increases in the share price;

- the possibility of obtaining higher prices when market conditions permit; positive return for the corporate image.

The main disadvantages are:

- the cost factor, this is considerably more expensive than the alternative disinvestment mechanisms; 


\section{PROOF}

The Intermediaries in the Risk Capital Industry 85

- lock-up clauses, which may prevent liquidation of the entire holding;

- the impossibility of using this option in the case of firms which are not of interest to the market, for example due to their small size.

If listing is the selected way out, the choice of market as described in chapter 7 is extremely important. Choosing the stock market on which a company intends to have its shares listed is crucial, especially with regard to the effects of this decision on corporate strategy overall. Apart from effects directly linked to the firm's financial management, membership of a financial market also has consequences for the company's image and credibility in relation to customers, suppliers and potential partners.

Normally, mergers and acquisitions represent the most common type of successful exit for risk capital investments and serve as an alternative to an initial public offering exit. However, it must be underlined that this form of exit is particularly complex, especially because the agreement of both the management and the other shareholders is required. The management may block operations of this kind if the buyer is an industrial partner, fearing possible substitutions. This way out is normally quicker, has none of the costs involved in stock market listing and is the only possible option in the case of many enterprises, and, finally, the buyer may be strategically interested in the company offered for sale and thus willing to offer a higher price.

Once the holding has been sold, the risk capital investor will be able to distribute the revenues from the sale to the limited partners. 